\title{
Coulisses
}

Revue de théâtre

25 | Hiver 2002

Varia

\section{Étudier le théâtre, dans le monde}

Présentation des actes des congrès de l'A.I.T.U, de Valleyfield et Québec, 1997, Dakar, 1999

\section{Maria S. Horne, Jean-Marc Larrue et Claude Schumacher}

\section{(2) OpenEdition}

12 Journals

Édition électronique

URL : http://journals.openedition.org/coulisses/6060

DOI : $10.4000 /$ coulisses. 6060

ISSN : 2546-9460

Éditeur

Presses universitaires de Franche-Comté

\section{Édition imprimée}

Date de publication : 1 janvier 2002

Pagination : 112-113

ISBN : 2-84627-052-X

ISSN : 1150-594X

\section{Référence électronique}

Maria S. Horne, Jean-Marc Larrue et Claude Schumacher, "Étudier le théâtre, dans le monde », Coulisses [En ligne], 25 | Hiver 2002, mis en ligne le 24 octobre 2019, consulté le 15 novembre 2019 URL : http://journals.openedition.org/coulisses/6060; DOI : 10.4000/coulisses.6060

Ce document a été généré automatiquement le 15 novembre 2019.

Coulisses 


\title{
Étudier le théâtre, dans le monde
}

Présentation des actes des congrès de l'A.I.T.U, de Valleyfield et Québec, 1997, Dakar, 1999

\author{
Maria S. Horne, Jean-Marc Larrue et Claude Schumacher
}

1 Depuis une vingtaine d'années, le champ des études et de la pratique théâtrales à l'Université ${ }^{1}$ connaît une progression constante et une formidable diversification. Les programmes se sont multipliés et ouverts à de nouveaux types d'activités, souvent multidisciplinaires, abordant autant la théorie que la création, la formation que la pédagogie. Ce développement se double d'un autre phénomène tout aussi marquant: l'accroissement considérable des compagnies et des rencontres théâtrales universitaires. Cette situation soulève une multitude de questions dont certaines ne datent pas d'hier. Celle du rapport et de l'apport de l'université au théâtre est de celleslà. Elle est, en effet, aussi vieille que la présence du théâtre dans les universités, collèges et autres établissements de l'ordre tertiaire. Mais le décloisonnement et la diversification des pratiques, tant dans les programmes et départements de théâtre ou autres que dans les activités universitaires moins encadrées, nécessitent une approche plus souple et plus ouverte que ce qu'offrent d'ordinaire les rencontres savantes traditionnelles. D'autant plus que le théâtre aussi évolue. Des besoins nouveaux apparaissent, d'autres sont à prévoir, d'autres ont tout simplement disparu.

2 Le rapport de l'université au théâtre est donc non seulement pluriel et polymorphe, il est aussi en perpétuelle mutation. On constate des mouvements de fond de plus en plus rapides et des transformations radicales. Dans certaines régions, on observe des rapprochements entre les écoles de formation professionnelle et les universités, les premières tentant parfois d'obtenir un statut universitaire, les secondes cherchant souvent des moyens de mieux adapter leur cursus au besoin du marché du théâtre. Ailleurs, on remarque une volonté de mise en commun des ressources et des énergies; ailleurs encore, on s'efforce de redéfinir des frontières et des aires de responsabilités. La question du rapport du théâtre universitaire avec la formation et le milieu professionnel est d'une brûlante actualité dans plusieurs régions du monde, et non des moindres. 
C'est donc à un bien vaste chantier que s'est risquée l'Association internationale du théâtre à l'Université (AITU) lorsqu'elle a proposé à ses membres de réfléchir collectivement à ces questions au cours de ses deux derniers congrès. D'accord avec le Comité exécutif de l'AITU, les comités organisateurs de ces deux congrès ont convenu de procéder par étape. Le premier congrès mondial concerné, qui a eu lieu en 1997 à Valleyfield et à Québec (Québec, Canada), avait un thème volontairement ouvert et général : « Étudier le théâtre : Recherche, formation et création ». Son objectif était de proposer un premier tableau d'ensemble de l'activité théâtrale à l'université sous toutes ses formes, à l'aube du troisième millénaire. Le congrès mondial suivant, qui s'est déroulé à Dakar (Sénégal) en 1999, a poursuivi la réflexion mais dans une perspective plus pointue encore : "L'Université et la formation professionnelle ».

Les deux congrès ont donné lieu à près de deux cents interventions scientifiques qui, tant par leur forme que par leur contenu, illustrent bien la diversité et, en même temps, la nécessaire complémentarité et la convergence des pratiques universitaires en matière théâtrale. L'université forme des théoriciens, mais elle a largement contribué et continue de contribuer à la formation de praticiens professionnels de la scène et à celle de formateurs (enseignants généralistes, spécialistes, etc.).

Quelle a été cette contribution dans le passé ? Quelle forme a-t-elle prise? Qu'en est-il ressorti? Et aujourd'hui, de quels moyens dispose l'université pour maintenir cette contribution? Qu'en fait-elle? Quelles avenues propose-t-elle dans le domaine de la formation, des pratiques créatrices, de la théorie et de la recherche théorique?

C'est donc à ce large éventail de questions, toutes liées à la mission de l'université à l'égard du théâtre, que quatre cents chercheurs, créateurs, praticiens, praticienschercheurs et formateurs du milieu universitaire issus du monde entier ont réfléchi pendant près de deux semaines à Valleyfield et Québec dans un premier temps, à Dakar dans un second. Les actes que le Comité de publication de l'AITU a décidé de produire à la suite de ces deux événements avec le concours des comités organisateurs concernés n'offrent qu'un tableau forcément restreint de l'entièreté et de la vigueur des échanges qui ont eu lieu mais ils illustrent bien la richesse et la variété de nos intérêts et de nos pratiques.

6 Ces actes, qui ne peuvent malheureusement pas rendre compte de ce type d'interventions dynamiques et précieuses que sont les démonstrations et les ateliers, reflètent cependant la dimension internationale de l'AITU.

\section{NOTES}

1. Conformément à la charte de l'AITU \IUTA, par *université+, nous entendons tout établissement relevant de l'ordre d'enseignement supérieur (collèges nord-américains, écoles supérieures, etc.). 


\section{AUTEURS}

\section{MARIA S. HORNE}

University at Buffalo, The State University of New York (États-Unis)

\section{JEAN-MARC LARRUE}

Collège de Valleyfiield (Québec, Canada)

\section{CLAUDE SCHUMACHER}

University of Glascow (United Kingdom) 